\title{
Iridium(III)-Catalyzed Dehydrogenative Coupling of Salicylic Acids with Alkynes: Synthesis of Highly Substituted 1-Naphthol Derivatives
}

\author{
Keishi Hirosawa, Yoshinosuke Usuki, Tetsuya Satoh
}

\begin{tabular}{|c|l|}
\hline Citation & Advanced Synthesis and Catalysis. 361(22); 5253-5257 \\
\hline Issue Date & 2019-11-19 \\
\hline Type & Journal Article \\
\hline $\begin{array}{c}\text { Supporting } \\
\text { information }\end{array}$ & $\begin{array}{l}\text { Supporting information for this article is available on the WWW under } \\
\text { https://doi.org/10.1002/adsc.201900919. }\end{array}$ \\
\hline Textversion & Author \\
\hline Rights & $\begin{array}{l}\text { This is the peer reviewed version of the following article: Advanced Synthesis and } \\
\text { Catalysis. Vol.361, Issu.22, pp.5253-5257. which has been published in final form at } \\
\text { https://doi.org/10.1002/adsc.201900919. This article may be used for non- } \\
\text { commercial purposes in accordance with Wiley Terms and Conditions for Use of } \\
\text { Self-Archived Versions. }\end{array}$ \\
\hline DOI & 10.1002/adsc.201900919 \\
\hline
\end{tabular}

\author{
Self-Archiving by Author(s) \\ Placed on: Osaka City University
}

Keishi Hirosawa, Yoshinosuke Usuki, Tetsuya Satoh. (2019). Iridium(III) - Catalyzed

Dehydrogenative Coupling of Salicylic Acids with Alkynes: Synthesis of Highly Substituted 1 -

Naphthol Derivatives. Advanced Synthesis and Catalysis. 361, 5253-5257.

doi:10.1002/adsc.201900919. 


\title{
Iridium(III)-Catalyzed Dehydrogenative Coupling of Salicylic Acids with Alkynes: Synthesis of Highly Substituted 1-Naphthol Derivatives
}

\author{
Keishi Hirosawa, ${ }^{a}$ Yoshinosuke Usuki, ${ }^{\mathrm{a}}$ and Tetsuya Satoh $^{\mathrm{a}, *}$ \\ a Department of Chemistry, Graduate School of Science, Osaka City University, 3-3-138 Sugimoto, Sumiyoshi-ku, \\ Osaka 558-8585, Japan \\ Fax: +81-6-6605-2522 \\ E-mail: satoh@sci.osaka-cu.ac.jp
}

Received: ((will be filled in by the editorial staff))

\begin{abstract}
The iridium(III)-catalyzed dehydrogenative coupling of salicylic acids with diarylacetylenes proceeds smoothly accompanied by decarboxylation to produce 5,6,7,8-tetraarylnaphthalen-1-ols selectively. This reaction can be conducted even without addition of external oxidant. The same kind of naphthalen-1-ol derivative can also be synthesized predominantly by the reaction of 4hydroxybenzoic acid with diphenylacetylene. Some of naphthalen-1-ols prepared exhibits unique optical properties.
\end{abstract}

Keywords: Carboxylic acids; C-C coupling; C-H activation; Homogeneous catalysis; Iridium

The transition-metal-catalyzed $\mathrm{C}-\mathrm{H}$ functionalization reactions have been recognized as useful tools in modern organic synthesis because of their atom- and step-economy. ${ }^{[1]}$ Various kinds of directing groups have been developed and utilized for regioselective $\mathrm{C}-\mathrm{H}$ bond cleavage at their neighboring position. ${ }^{[2]} \mathrm{A}$ carboxylic group loaded on aromatic substrates is a unique directing group because of its ready removability, which allows regioselective functionalization at its ortho- as well as ipsoposition. ${ }^{[3]}$ For example, we have reported that benzoic acid undergoes iridium(III)-catalyzed decarboxylative, dehydrogenative coupling with diarylacetylenes accompanied by carboxyl groupdirected ortho $\mathrm{C}-\mathrm{H}$ bond cleavage and subsequent decarboxylation to produce highly substituted naphthalenes (Scheme 1a, R = H) ${ }^{[4,5]}$ This enables aromatic homologation providing a simple synthetic route to fused aromatic compounds from readily available arenecarboxylic acids. Actually, the reactions of meta- and para-substituted benzoic acids with diarylacetylene selectively give 2-substituted 5,6,7,8-tetraarylnaphthalenes. However, this procedure is not applicable to the synthesis of 1substituted 5,6,7,8-tetraarylnaphthalenes from ortho-

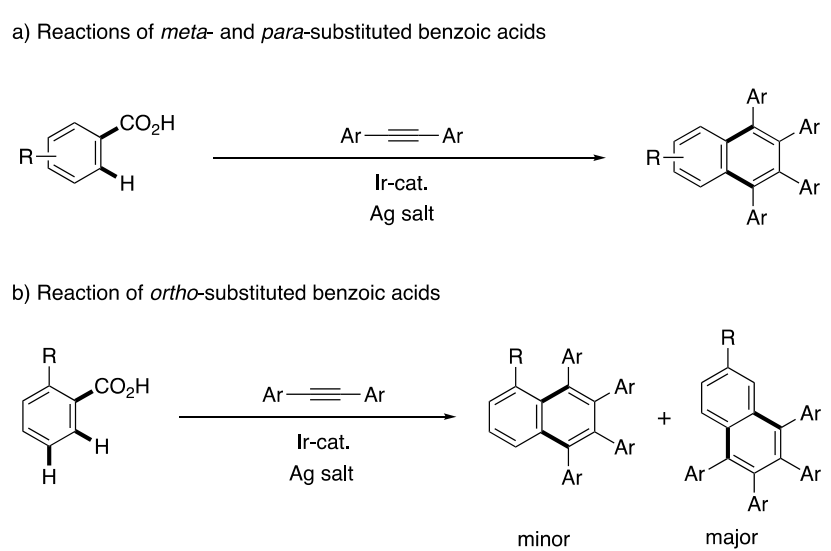

c) Plausible mechanism

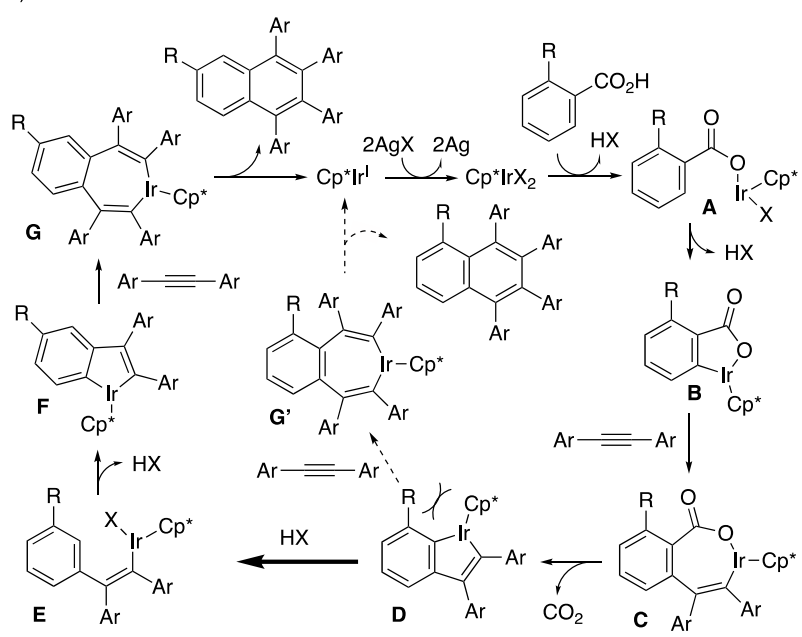

d) This work

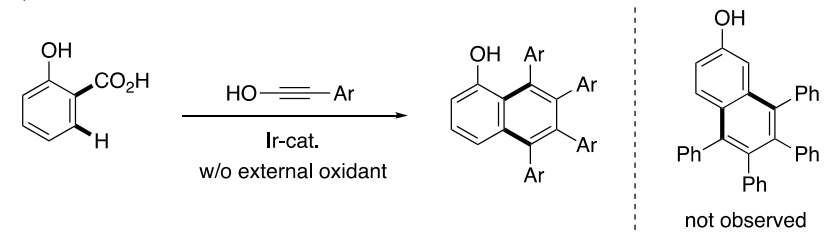


Scheme 1. Decarboxylative Coupling of Benzoic Acids with Diarylacetylenes.

substituted benzoic acids. This reaction seems to involve isomerization of metallacycle intermediate $\mathbf{D}$, generated through cyclometallation, alkyne insertion, and decarboxylation steps, to $\mathbf{F}$ due to steric hindrance to give 2-substituted 5,6,7,8tetraarylnaphthalenes predominantly (Schemes $1 \mathrm{~b}$ and $1 \mathrm{c}) \cdot{ }^{[4,5]}$

During our further studies on the annulation of (hetero)arenecarboxylic acids, ${ }^{[6]}$ we have found that ortho-hydroxybenzoic acids, salicylic acids, couple with diarylacetylenes at the sterically crowded positions to exclusively produce 5,6,7,8tetraarylnaphthalen-1-ols (Scheme 1d). ${ }^{[7]}$ This dehydrogenative coupling proceeds smoothly even under external oxidant-free conditions. It should be noted that peri-arylated 1-naphthol derivatives have gained much attention due to their optical properties induced by the interaction between their peri-hydroxy and aryl groups. ${ }^{[8]}$ Unexpectedly, the sterically hindered 5,6,7,8-tetraphenylnaphthalen-1-ol can also be prepared predominantly in the reaction of parahydroxybenzoic acid with diphenylacetylene. These results are described herein.

In an initial attempt, salicylic acid (1a) $(0.3 \mathrm{mmol})$ was treated with diphenylacetylene (2a) $(0.9 \mathrm{mmol})$ in the presence of $\left[\mathrm{Cp}^{*} \mathrm{IrCl}_{2}\right]_{2} \quad(0.01 \mathrm{mmol}, 3.3$ mol \%), $\operatorname{AgSbF}_{6}(0.04 \mathrm{mmol})$, and $\mathrm{Cu}(\mathrm{OAc})_{2} \cdot \mathrm{H}_{2} \mathrm{O}$ $(0.05 \mathrm{mmol})$ in xylene under $\mathrm{O}_{2}(1 \mathrm{~atm})$ at $170{ }^{\circ} \mathrm{C}$ for $23 \mathrm{~h}$. As a result, 5,6,7,8-tetraphenylnaphthalen-1-ol (3aa) was selectively formed in 53\% GC yield (Table 1 , entry 1). In the reaction mixture, almost the same amount $(0.16 \mathrm{mmol})$ of stilbene was also detected by GC and GC-MS. The fact suggests that alkyne $\mathbf{2 a}$ can act as hydrogen accepter in the present dehydrogenative coupling system. ${ }^{[9]}$ Therefore, we next eliminated $\mathrm{Cu}(\mathrm{OAc})_{2} \cdot \mathrm{H}_{2} \mathrm{O}(0.05 \mathrm{mmol})$ and $\mathrm{O}_{2}$ (entry 2). As expected, even under such conditions without external oxidant, 3aa was obtained in $69 \%$ yield (entry 2). At $150{ }^{\circ} \mathrm{C}$, the reaction was sluggish (entry 3). The addition of $\mathrm{AgSbF}_{6}$ as a cocatalyst was found to be essential for the reaction. Thus, the yield of 3aa considerably decreased in the absence of $\mathrm{AgSbF}_{6}$ (entry 4). Other silver salts such as AgOAc and $\mathrm{AgNTf}_{2}$ were less effective than $\mathrm{AgSbF}_{6}$ (entries 5 and 6 versus entry 2). Finally, slight increase of reaction temperature to $180{ }^{\circ} \mathrm{C}$ enhanced the yield up to $75 \%$ (entry 7 ). In addition, the reaction could be readily scaled up to a $1 \mathrm{mmol}$ scale. Thus, the reaction of $\mathbf{1 a}(1 \mathrm{mmol})$ with $\mathbf{2 a}(3 \mathrm{mmol})$ gave 3aa in a reasonable yield $(314 \mathrm{mg}, 70 \%)$ (entry 8$)$.

Under the conditions in entry 7 of Table 1 , the reactions of $1 \mathbf{a}$ with various alkynes $\mathbf{2 b}$-g were next examined (Table 2). Diphenylacetylenes possessing methyl-, tert-butyl-, methoxy-, and chlorosubstituents at the para positions $\mathbf{2 b}$-e underwent the coupling to produce the corresponding 5,6,7,8tetraarylnaphthalen-1-ols 3ab-ae. The reactions with electron-deficient (trifluoromethyl)phenyl]acetylene (2f) and 4-octyne (2g) did not proceed at all. ${ }^{[10]}$ Meanwhile, variously substituted salicylic acids are now commercially available. Some of them were

Table 1. Reaction of Salicylic Acid (1a) with Diphenylacetylene $(\mathbf{2 a})^{[\mathrm{a}]}$.

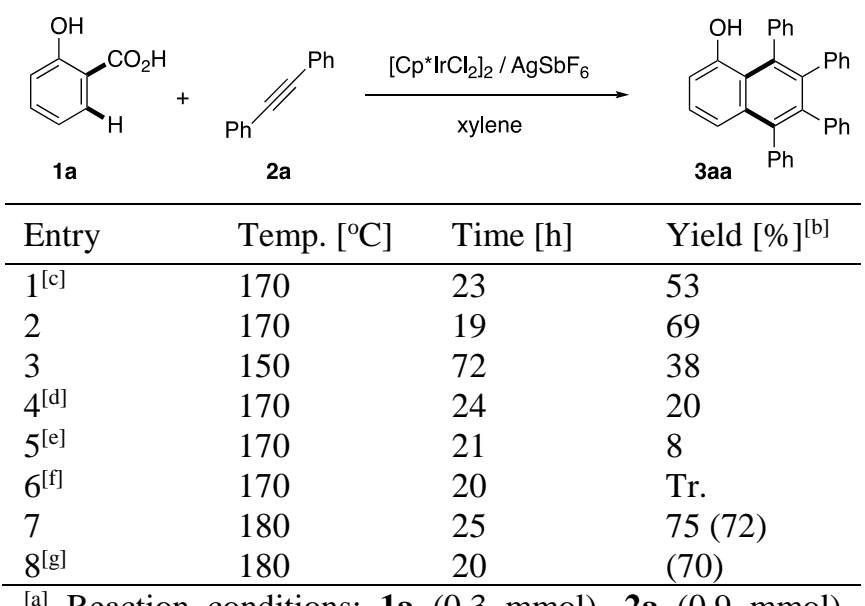

$\left[\mathrm{Cp}^{*} \mathrm{IrCl}_{2}\right]_{2}(0.01 \mathrm{mmol}), \mathrm{AgSbF}_{6}(0.04 \mathrm{mmol})$ in xylen $(2.5 \mathrm{~mL})$ under $\mathrm{Ar}$, unless otherwise noted. ${ }^{[\mathrm{b}]} \mathrm{GC}$ yield based on the amount of 1a used. Value in parentheses

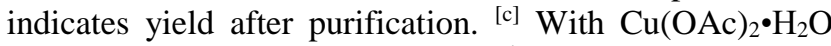
$(0.05 \mathrm{mmol})$ under $\mathrm{O}_{2}(1 \mathrm{~atm})$. [d] Without $\mathrm{AgSbF}_{6}$. ${ }^{[\mathrm{e}]}$ AgOAc was employed in place of $\mathrm{AgSbF}_{6}{ }^{[\mathrm{f}]} \mathrm{AgNTf}_{2}$ was employed in place of $\mathrm{AgSbF}_{6}$. ${ }^{[\mathrm{g}]} \mathbf{1 a}(1 \mathrm{mmol}), \mathbf{2 a}$ (3 $\mathrm{mmol}),\left[\mathrm{Cp}^{*} \mathrm{IrCl}_{2}\right]_{2}(0.03 \mathrm{mmol}), \mathrm{AgSbF}_{6}(0.13 \mathrm{mmol})$, and xylene $(7 \mathrm{~mL})$ were employed.

employed for the coupling with $\mathbf{2 a}$. The reactions of 4-chloro- (1b), 3-methoxy- (1c), and 3,4-dimethoxysalicylic acid (1d) gave 3-chloro- (3ba), 2-methoxy(3ca), and 2,3-dimethoxy- (3da) 5,6,7,8tetraphenylnaphthalen-1-ols in $45-68 \%$ yields. 2,5,6,7,8-Pentaphenylnaphthalen-1-ol (3ea) could also be synthesized in $62 \%$ yield from 3phenylsalicylic acid (1e) and 1a. In contrast, 3nitrosalicylic acid (1f) and 1-hydroxy-2-naphthoic acid (1g) did not react with $\mathbf{2 a}$ at all. 
Table 2. Reaction of Salicylic Acids 1 with Alkenes $2^{[\mathrm{a}]}$.

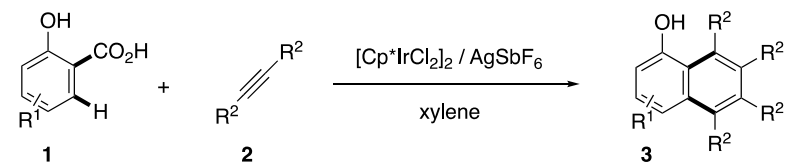

product $\%$ yield $^{b}$
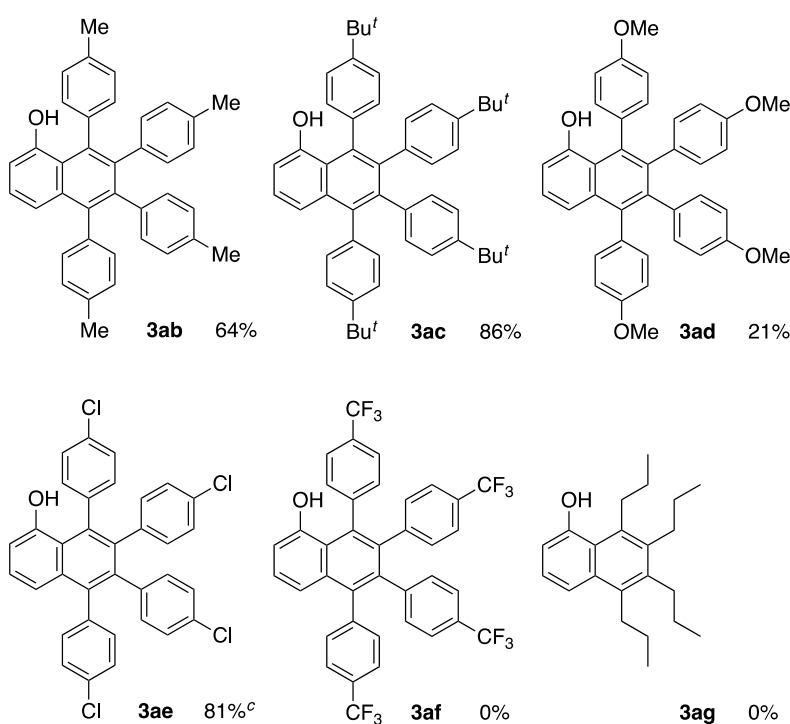

3ag $0 \%$
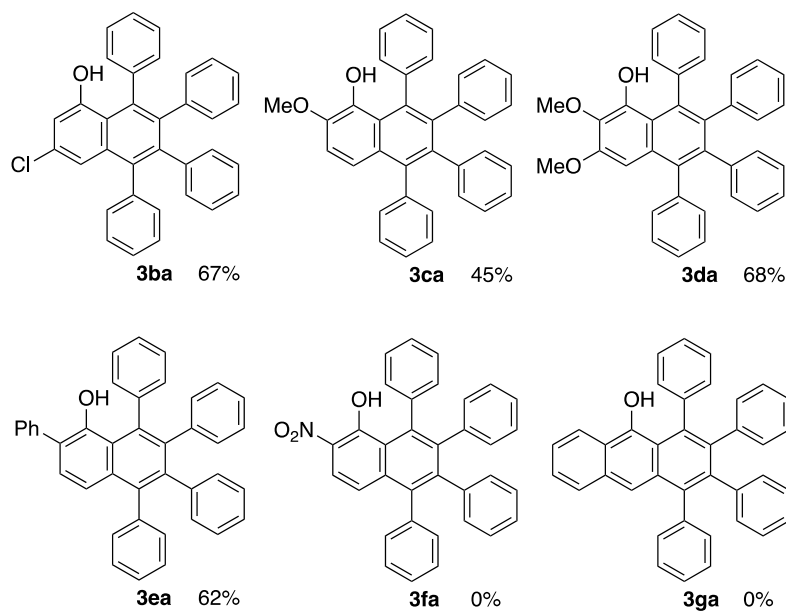

[a] Reaction conditions: 1 (0.3 mmol), 2 (0.9 mmol), $\left[\mathrm{Cp}^{*} \mathrm{IrCl}_{2}\right]_{2}(0.01 \mathrm{mmol}), \mathrm{AgSbF}_{6}(0.04 \mathrm{mmol})$ in xylene $(2.5 \mathrm{~mL})$ at $180{ }^{\circ} \mathrm{C}$ under $\mathrm{Ar}$ for $24 \mathrm{~h}$, unless otherwise noted. ${ }^{[b]}$ Isolated yield based on the amount of $\mathbf{1}$ used. ${ }^{[\mathrm{c}]} \mathbf{1}$ (0.1 mmol), 2 (0.3 mmol), [Cp* $\left.\mathrm{IrCl}_{2}\right]_{2}$ (0.003 mmol), $\mathrm{AgSbF}_{6}(0.013 \mathrm{mmol})$ were used.

As described above, the reaction of parahydroxybenzoic acid (4) with $\mathbf{2 a}$ also gave 5,6,7,8tetraphenylnaphthalen-1-ol (3aa) predominantly, along with a minor amount of 5,6,7,8tetraphenylnaphthalen-2-ol (5) (Scheme 2). This preference is rather unexpected because 3aa seems to be sterically crowded compared to $\mathbf{5}$.

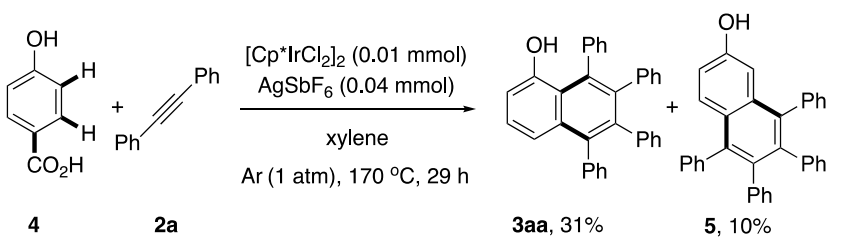

Scheme 2. Reaction of 4 with $\mathbf{2 a}$.

Plausible pathways for the reactions of $\mathbf{1}$ and $\mathbf{4}$ with $\mathbf{2}$ are depicted in Scheme 3. The reaction of salicylic acid $\mathbf{1}$ with alkyne $\mathbf{2}$ appears to proceed in a similar way to that shown in Scheme 1c, through carboxyl group-directed $\mathrm{C}-\mathrm{H}$ bond cleavage to form $\mathbf{B}$, alkyne insertion to form $\mathbf{C}$, decarboxylation to form $\mathbf{D}$, the second alkyne insertion, and reductive elimination steps. The $\mathrm{Cp}^{*} \operatorname{Ir}^{\mathrm{I}}$ species formed at the last step seems to be reoxidized in the presence of 2 and $\mathrm{HX}$ to generate an active $\mathrm{Cp}^{*} \mathrm{Ir}^{\mathrm{III}} \mathrm{X}_{2}$ species. ${ }^{[9,11]}$ Exclusive formation of 1-naphthol 3 indicates that the path from intermediate $\mathbf{D}$ toward the second alkyne insertion leading to the formation of $\mathbf{3}$ is preferred rather than that involving isomerization to form $\mathbf{5}$. In the reaction of para-hydroxybenzoic acid $\mathbf{4}$, on the other hand, a similar five-membered metallacycle intermediate $\mathbf{F}$ may be formed in a similar manner to that of $\mathbf{D}$. The fact, predominant formation of 3aa in Scheme 2, suggests that $\mathbf{F}$ may undergo isomerization to $\mathbf{D}$ via $\mathbf{E}$. It is possible that coordination of the hydroxy group ${ }^{[12]}$ of $\mathbf{D}$ toward its Ir center is a key to stabilize the intermediate $\mathbf{D}$ and promote the isomerization to lead to preferential formation of 3aa.

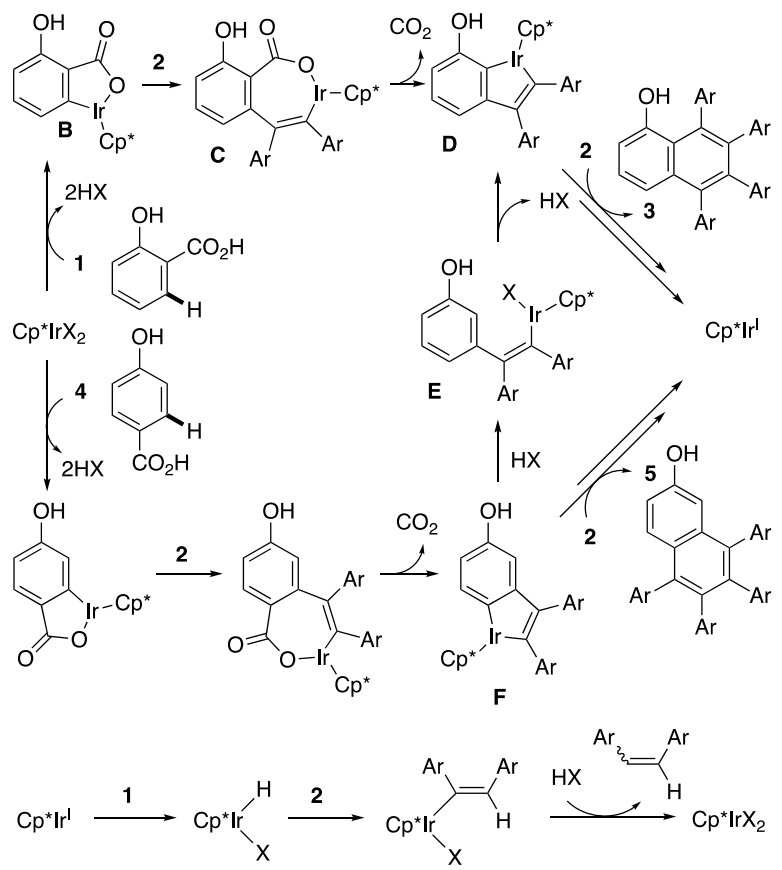

Scheme 3. Reaction Pathways to Produce 3 and 5.

As expected, substituting methoxy group for the hydroxy altered the predominant pathway. Thus, as shown in Scheme 4, treatment of ortho- 
methoxybenzoic acid (6) with $\mathbf{2 a}$ under the standard conditions gave 2-methoxy-5,6,7,8tetraphenylnaphthalene (7) predominantly, along with a minor amount of 1-methoxy isomer (8).

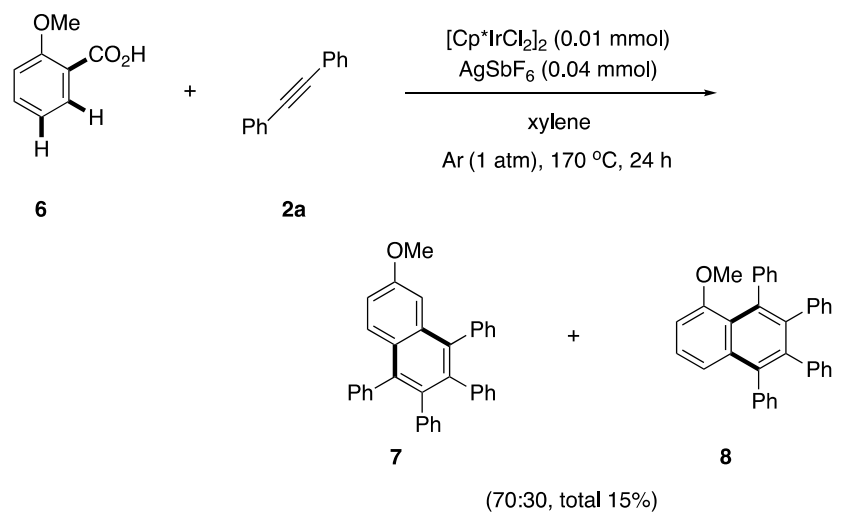

Scheme 4. Reaction of 6 with $2 \mathbf{a}$.

It has been reported that 8-arylnaphthalen-1-ol derivatives show interesting photophysical properties of a bathochromic shift of emission and a large Stokes shift. ${ }^{[8]}$ These appear to be due to the throughspace interaction between the peri-hydroxy and aryl groups stabilizing the excited state. Therefore, the products 5,6,7,8-tetraarylnaphthalen-1-ols possessing an aryl group at the peri-position are expected to show similar properties. In a preliminary investigation on the optical properties of 3aa, a large Stokes shift was also observed in the measured emission and excitation spectra in DMSO solution (Figure 1).
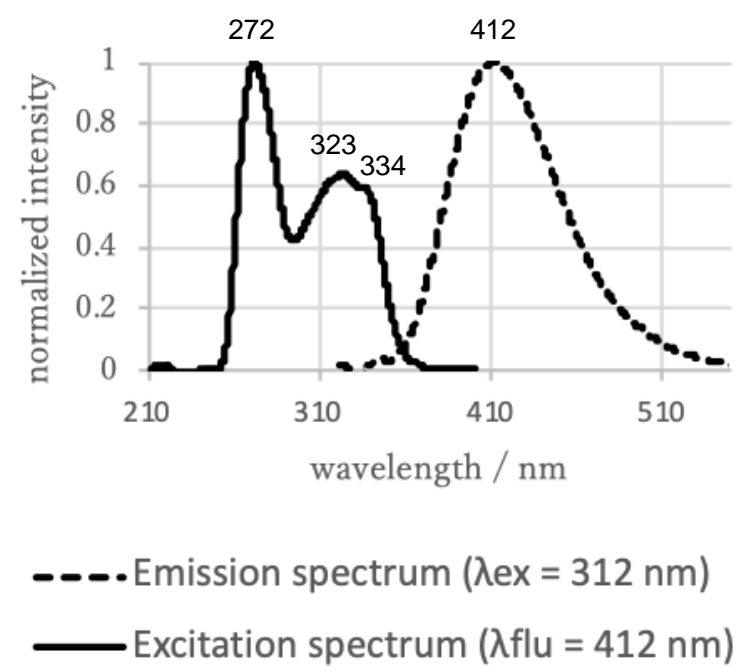

Figure 1. Emission and Excitation Spectra of 3aa in DMSO Solution (0.01 mM).

In conclusion, we have demonstrated that salicylic acids undergo dehydrogenative, decarboxylative coupling upon treatment with diarylacetylenes in the presence of a iridium(III) catalyst to give 5,6,7,8- tetraarylnaphthalen-1-ols. The reaction of 4hydroxybenzoic acid has also been found to give the same naphthalen-1-ol derivative predominantly. Plausible reaction pathways have been proposed. Work is underway for further understanding the mechanism.

\section{Experimental Section}

Experimental Details: To a $20 \mathrm{~mL}$ two-necked flask with a reflux condenser, a balloon, and a rubber cup were added salicylic acid $1(0.3 \mathrm{mmol}),\left[\mathrm{Cp}^{*} \mathrm{IrCl}_{2}\right]_{2}(0.01 \mathrm{mmol}, 8 \mathrm{mg})$, $\mathrm{AgSbF}_{6}(0.04 \mathrm{mmol}, 14 \mathrm{mg})$, and xylene $(2.5 \mathrm{~mL})$. The mixture was stirred under air at room temperature for 10 min. Then, alkyne $2(0.9 \mathrm{mmol})$ and 1 -methylnaphthalene (ca. $50 \mathrm{mg}$ ) as internal standard were added and the resulting mixture was stirred under $\arg$ on $(1 \mathrm{~atm})$ at $180{ }^{\circ} \mathrm{C}$ (bath temperature) for $24 \mathrm{~h}$. The reaction mixture was diluted by ethyl acetate $(50 \mathrm{~mL})$. The organic layer was washed by water $(50 \mathrm{~mL}$, two times $)$ and brine $(50 \mathrm{~mL})$ and dried over $\mathrm{Na}_{2} \mathrm{SO}_{4}$. After evaporation of the solvents under vacuum, product $\mathbf{3}$ was isolated by column chromatography on silica gel using hexane-ethyl acetate as eluent. Further purification by GPC (gel permeation chromatography) was performed, if needed.

\section{Acknowledgements}

This work was supported by JSPS KAKENHI Grant Numbers $18 H 04267$ (in Precisely Designed Catalysts with Customized Scaffolding) and 18K19083 (Grant-in-Aid for Challenging Research (Exploratory)), Nagase Science Technology Foundation, and Yamada Science Foundation to T.S. and JSPS KAKENHI Grant Number JP18H04627 (in Frontier Research on Chemical Communications) to Y.U. We also thank Prof. M. Yasuda (Osaka University) for helpful discussions.

\section{References}

[1] For selected reviews for $\mathrm{C}-\mathrm{H}$ functionalization, see: a) C. Sambiagio, D. David Schöbauer, R. Blieck, T. DaoHuy, G. Pototschnig, P. Schaaf, T. Wiesinger, M. F. Zia, J. Wencel-Delord, T. Besset, B. U. W. Maes, M. Schnürch, Chem. Soc. Rev. 2018, 47, 6603; b) M. Gulías, J. L. Mascareñas, Angew. Chem. 2016, 128, 11164; Angew. Chem., Int. Ed. 2016, 55, 11000; c) Z. Chen, B. Wang, J. Zhang, W. Yu, Z. Liu, Y. Zhang, Org. Chem. Front. 2015, 2, 1107; d) G. Song, X. Li, Acc. Chem. Res. 2015, 48, 1007; e) J. Ye, M. Lautens, Nature Chem. 2015, 7, 863; f) M. Miura, T. Satoh, K. Hirano, Bull. Chem. Soc. 2014, 87, 751; g) S. De Sarkar, W. Liu, S. I. Kozhushkov, L. Ackermann, $A d v$. Synth. Catal. 2014, 356, 1461; h) J. Wencel-Delord, F. Glorius, Nat. Chem. 2013, 5, 369; i) D. A. Colby, A. S. Tsai, R. G. Bergman, J. A. Ellman, Acc. Chem. Res. 2012, 45, 814; j) K. M. Engle, T.-S. Mei, M. Wasa, J.Q. Yu, Acc. Chem. Res. 2012, 45, 788; k) S. H. Cho, SJ. Y. Kim, J. Kwak, S. Chang, Chem. Soc. Rev. 2011, 40, 5068; 1) R. Giri, B.-F. Shi, K. M. Engle, N. Maugel, J.Q. Yu, Chem. Soc. Rev. 2009, 38, 3242.

[2] For pioneering work, see: S. Murai, F. Kakiuchi, S. Sekine, Y. Tanaka, A. Kamatani, M. Sonoda, N. Chatani, Nature 1993, 366, 529. 
[3] For representative reviews, see: a) Y. Wei, P. Hu, M. Zhang, W. Su, Chem. Rev. 2017, 117, 8864; b) M. Font, J. M. Quibell, G. J. P. Perry, I. Larrosa, Chem. Commun. 2017, 53, 5584; c) M. P. Drapeau, L. J. Goossen, Chem. Eur. J. 2016, 23, 18654; d) T. Satoh, M. Miura, Synthesis 2010, 3395.

[4] K. Ueura, T. Satoh, M. Miura, J. Org. Chem. 2007, 72, 5362.

[5] Other groups also reported similar annulation: a) Y. Honjo, Y. Shibata, E. Kudo, T. Namba, K. Masutomi, K. Tanaka, Chem. Eur. J. 2018, 24, 317; b) V. P. Datsenko, Y. V. Nelyubina, A. F. Smol'yakov, D. A. Loginov, J. Organomet. Chem. 2018, 874, 7; c) D. A. Loginov, V. E. Konoplev, J. Organomet. Chem. 2018, 867,14 ; d) D. A. Loginov, A. O. Belova, A. R. Kudinov, Russ. Chem. Bull., Int. Ed. 2014, 63, 983.

[6] a) T. Okada, A. Sakai, T. Hinoue, T. Satoh, Y. Hayashi, S. Kawauchi, K. Chandrababunaidu, M. Miura, J. Org. Chem. 2018, 83, 5639; b) T. Okada, Y. Unoh, T. Satoh, M. Miura, Chem. Lett. 2015, 44, 1598; c) M. Yamashita, H. Horiguchi, K. Hirano, T. Satoh, M. Miura, J. Org. Chem. 2009, 74, 7481; d) M. Shimizu, K. Hirano, T. Satoh, M. Miura, J. Org. Chem. 2009, 74, 3478.

[7] For a precedent reporting the synthesis of 5,6,7,8Tetraarylnaphthalen-1-ols via the rhodium-catalyzed coupling of 2-phenoxypyridines with alkynes, see: L. Wang, Y. Yu, M. Yang, C. Kuai, D. Cai, J. Yu, X. Cui, Adv. Synth. Catal. 2017, 359, 3818. However, in this case, additional steps for the introduction and removal of the pyridyl directing group were needed to reduce the atom- and step-economy.
[8] H. Nakajima, M. Yasuda, K. Shimizu, N. Toyoshima, Y. Tsukahara, T. Kobayashi, S. Nakamura, K. Chiba, A. Baba, Bull. Chem. Soc. Jpn. 2011, 84, 1118.

[9] For example, see: a) L. C. Misal Castro, N. Chatani, Chem. Lett. 2015, 44, 410; b) W. Song, L. Ackermann, Chem. Commun. 2013, 49, 6638.

[10] Actually, the addition of $\mathbf{2 g}$ suppressed the reaction of 1a with 2a. Thus, treatment of $1 \mathbf{a}(0.3 \mathrm{mmol}), \mathbf{2 a}(0.6$ $\mathrm{mmol})$, and $2 \mathrm{~g}(0.6 \mathrm{mmol})$ under standard conditions did not give any coupling products at all.

[11] For previous reports concerning oxidative addition of benzoic acid to $\operatorname{Ir}^{\mathrm{I}}$ species, see: a) T. Yamagata, $\mathrm{H}$. Tadaoka, M. Nagata, T. Hirao, Y. Kataoka, V. Ratovelomanana-Vidal, J.-P. Genet, K. Mashima, Organometallics 2006, 25, 2505; b) H. Werner, A. Höhn, M. Dziallas, T. Dirnberger, Dalton Trans. 2006, 2597.

[12] A similar directing effect by a hydroxy group has been reported: C.-H. Yeh, W.-C. Chen, P. Gandeepan, Y.-C. Hong, C.-H. Shih, C.-H. Cheng, Org. Biomol. Chem. 2014, 12, 9105. 


\section{UPDATE}

Iridium(III)-Catalyzed Dehydrogenative Coupling of Salicylic Acids with Alkynes: Synthesis of

Highly Substituted 1-Naphthol Derivatives

Adv. Synth. Catal. Year, Volume, Page - Page

Keishi Hirosawa, Yoshinosuke Usuki, and Tetsuya

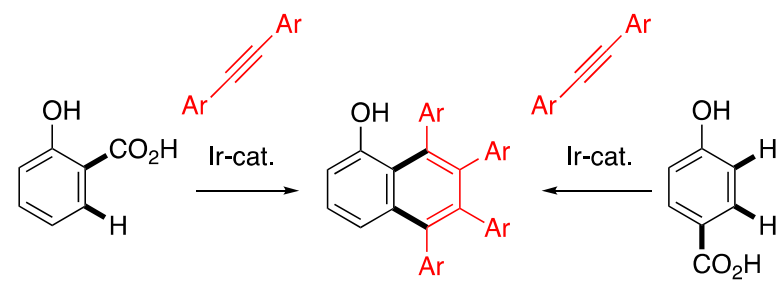

Satoh* 